Journal of Tourism Theory and Research

Online, http://dergipark.gov.tr/jttr

Volume: 5(1), 2019

ISSN: $2548-7583$

\title{
A critical view on the paradox of slow city - sustainable tourism
}

\author{
Yeşim Coşar $^{1}$
}

\begin{abstract}
When the world tourism sector faced serious problems before entering the new millennium, the question of "what could be done?" started to be asked more intensely in order to make us think. What were these problems? Firstly, it was marketing of certain types of products. The other problem was that tourism activities were similar in countries or regions. Therefore, different regions or countries had to meet the tourism market by introducing alternative products. While focusing on individual tourism, mass tourism has emerged such as emergence of luxury tourism, coastal tourism, social and culture/city tourism. Similarly, as in hotels, all-inclusive concept has emerged as an alternative product to bed \& breakfast or halfboard. Perhaps in the future, nothing inclusive could be an alternative product to all inclusive. Suddenly slow-food appeared as an alternative to fast-food. With the success of the slow food movement, the concept of slow-city came out. This study focuses on the concepts of slow city and slow tourism which are alternative to mass tourism made with package tours, and the study will analyse how these two terms conflict with each other in tourism context. The concept of slow city and sustainable development supports each other. The purpose of concept of slow cities is to increase public investment and living standards in cities, to revive the local economy, to protect and maintain cultural and natural resources. However, in recent years, especially when the slow cities examined in our country, some developments that go against the spirit slow city has emerged. This study aims to form a critical view by slow city practice in our country and the aim of slow cities.

Keywords: Slow city, cittaslow, sustainable tourism
\end{abstract}

\section{Yavaş şehir-sürdürülebilir turizm paradoksu üzerine eleştirel bir bakış}

\section{$\ddot{O} z$}

Daha yeni milenyuma girmeden dünya turizm sektörü ciddi sorunlarla karşı karşlya kalınca, neler yapılabilir sorusu daha yoğun sorulmaya ve bizleri düşündürmeye başladl. Nelerdi bu tür sorunlar? Hep belirli tip ürünlerin pazarlanmasl, oysa insanlar bir dönemden diğerine farklılık arayabiliyorlardl. Bir başkası da, hep benzer ülke ya da bölgelerde turizm faaliyetlerinin görülmesi idi. Bunun için de, farklı bölgelerin ya da ülkelerin alternatif ürünler olarak turizm piyasası ile tanışması gerekiyordu. Nasıl mı? Bireysel turizm derken karşısına kitle turizmi çıktı. Sosyal turizm derken lüks turizm, kültür/şehir turizmi derken kıyı turizminin ortaya çıkması gibi. Otellerden örnek vermek gerekirse, oda-kahvaltı ya da yarım pansiyonun karşısına herşey dahilin alternatif olması. Belki de ileride bunun karşısına da hiçbir şey dahil uygulamasının başlaması. Fast-food (ayakta yemek) derken birden slow-food (yavaş yemek) konuşmaya başladı. Yavaş yemek hareketinin başarısı ile birlikte slow-city (yavaş şehir) kavramı oraya çıktı. Bu çalışmada da paket turlarla yapılan kitlesel turizmin karşısına alternatif olan yavaş şehir ve yavaş turizm kavramlarına ve bunların turizm bağlamında taşıdığ zıtllğa değinmeye çalışacağız. Yavaşşsehir anlayışının sürdürülebilir kalkınma ile birbirini desteklediğini görüyoruz. Yavaşşshirlerin var oluş amacı şehirlerdeki kamu yatırımlarının ve yaşam standartlarının yükseltilmesi, yerel ekonominin canlanması, kültürel ve doğal kaynakların korunması ve yaşatılması gibi uygulamalardır. Ancak son yıllarda özellikle ülkemizdeki yavaşşsehirleri incelediğimizde bunun aksine gelişmeler yaşandiğı gözlemlenmektedir. Bu çalı̧̧mada yavaş şehirlerin var oluş amact ile ülkemizdeki uygulamalar üzerine yapılan çalışmalar incelenerek eleştirel bir bakış getirilmeye çalışılmıştır.

Anahtar sözcükler: Yavaş şehir, cittaslow, sürdürülebilir turizm.

$\begin{array}{ll}\text { Gönderilme tarihi } & : 26.10 .2018 \\ \text { Düzeltme tarihi } & : 28.12 .2018 \\ \text { Kabul edilme tarihi } & : 01.01 .2019\end{array}$

Alıntı için: Coşar, Y. (2019). Yavaş şehir-sürdürülebilir turizm paradoksu üzerine eleştirel bir bakış. Journal of Tourism Theory and Research, 5(1), 40-50. DOI: $\underline{\text { https://dx.doi.org/10.24288/jttr.476350 }}$

' Dr. Öğretim Üyesi, Dokuz Eylül Ün., Turizm İşl. ve Otelcilik Bölümü, Seferihisar Fevziye Hepkon UBY, İzmir. yesim.cosar@deu.edu.tr 


\section{Giriş}

Küreselleşme sürecinin etkileri, tüm dünyada ekonomik, kültürel, siyasi ve toplumsal alanlarda hissedilmektedir. Bütün yaşam çevrelerini etkisi altına alan küreselleşme, beraberinde yeni değişim hareketleri ve tepkilerin ortaya çıkmasına neden olmuştur. $\mathrm{Bu}$ değişiklerin sonucunda önümüzdeki yıllarda uluslararası turizmde yeni ülkelerin ve farklı ürünlerin piyasaya gireceği öngörülmektedir. Dünyada birçok kavram ya da uygulamanın zitlıklar üzerine kurulduğunu görüyoruz. Zengin karşısında yoksul, kapitalizm karşısında sosyalizm, batı karşısında doğu vb. kavramlar gibi. Görünen o ki, turizm sektörü de kendi geleceğini ya da dönüşümünü bu tür zitlıklar üzerine kurgulamaktadır.

Her zitlık bir alternatife işaret ediyor. Günümüzde yaşadığımız metropoller ve hızlı yaşam karşısında var olan olgu ise yavaşlıktır. Yavaşlık anlayışının karşı olduğu hız kavramının, dünya üzerinde bir kargaşa ortamı yarattığ 1 düşüncesinden ortaya çıkmış olduğu düşünülebilir. Oysa küreselleşmenin ve hızın ulaşamadığı pek çok yerleşim merkezinde yavaşlık, insan yaşamının normal bir akışı olarak görülmektedir. Çünkü henüz bu bölgelerde küreleşmenin doğal bir baskısı olarak ortaya çıkan hızlı ve dinamik yaşama, yer değiştirme, teknolojiye bağımlı olma gibi insan yaşamının büyük çoğunluğunu oluşturan örnekler en alt düzeyde olup, günlük geleneksel yaşamın bir parçası olan rahat ve sakin bir ortama sahip olma daha öncelikli olabilmektedir.

Son yıllarda yaşanan gelişmeler küreselleşmenin bir sonucu olan yerel kimliğin yok olmasının önüne geçilmesinin gerekliliğini ortaya koymaktadır. Hızlı şehirleşme ve sıradanlaşma insanları sakin, yerel kimliğini kaybetmemiş şehirlere yöneltmeye başlamıştır. Yerel kültürün korunması, organik gıda üretimi ve tüketimi gibi konularda çalışmaların yoğunlaştığını görmekteyiz. Bunun sonucu olarak dünyada yavaş akımlar ortaya çıkmıştır. İzmir'in Seferihisar ilçesi ülkemizde yavaş şehrin ilk örneğidir.

Yavaş şehir hareketi yerel değerleri koruyan, yaşam kalitesini arttırmayı hedefleyen, sürdürülebilir kentsel gelişim modelini benimseyen ve yerel yönetimler tarafindan desteklenen uluslararası bir organizasyondur. Ülkemizde var olan mevcut yavaş şehir uygulamalarına baktığımızda ise bazı noktalarda yavaş şehir felsefesi ile örtüşmeyen uygulamalara rastlamaktayız. Bu çalışmada yavaş şehir felsefesine uygun olmayan uygulamalar irdelenerek, yavaş şehir felsefesinin benimsenmesine yönelik önerilere yer verilmiştir.

\section{Yavaş şehir kavramı}

Yavaş yemek hareketini kentsel boyuta taşımak amacı ile kurulan yavaş şehir hareketi 1999 yılında İtalya'da ortaya çıkmış ve günümüzde 28 ülkede 182 üyeye sahiptir (http://cittaslowturkiye.org). 28 Kasım 2009 tarihinde İzmir ilinin Seferihisar ilçesinin yavaş şehir unvanına sahip olması ile birlikte Türkiye yavaş şehir ile tanışmıştır. Mevcut olarak ülkemizde Akyaka (Muğla), Gökçeada (Çanakkale), Halfeti (Şanlıurfa), Perşembe (Ordu), Seferihisar (İzmir), Şavşat (Artvin), Taraklı (Sakarya), Uzundere (Erzurum), Vize (Kırklareli), Yalvaç (Isparta) olmak üzere 11 adet yavaş şehir bulunmakta iken çalışmanın devam ettiği tarih itibari ile bu illere Gerze (Sinop), Göynük (Bolu), Eğridir (Isparta) ve son olarak 2018 yılında Mudurnu (Bolu) eklenerek sayıları 15 olmuştur.

Yavaş şehir kavramı, günümüz modern şehir kavramına alternatif olarak ortaya atılmış bir kavramdır. Daha çok o şehirde yaşam süren yerel halkın, doğası ve kültürü bozulmamış bir ortamda, çevre kirliliğinden uzak bir şekilde günlük yaşamını belirli bir konfor içerisinde devam ettirmesini hedeflemektedir (Mayer ve Knox 2006).Yavaş şehir kriterleri çevre, altyapı, kentsel kalite için teknoloji ve tesisler, yerel üretimin korunması ve konukseverlikten oluşan yedi ana başlıktan oluşmaktadır (http://cittaslowturkiye.org).Yavaş şehir kriterleri ile sürdürülebilir turizm ilkelerinin birbirleri ile örtüştüğü görülmektedir.

Yavaş şehir akımının önemsediği ilkeler arasında bölgenin dokusunun karakteristik özelliğinin korunması ve geliştirilmesine yönelik uygulanan bir çevre politikası; bölgede oturmak için değil ona değer verildiği için, onu bozmayan fonksiyonel olarak uygulanan bir altyapı politikası; çevrenin ve şehir dokusunun kalitesini arttırmaya yönelik teknoloji kullanımı, geri kazanım ve geri dönüşüm tekniklerine değer verilmesi, genetiği değiştirilmiş gıdalar yerine doğal teknikler ile elde edilen ve doğaya uyumlu gıda maddelerinin üretim ve tüketiminin sağlanması, su ve toprak kalitesinin önemsenmesi, çevreye uyumlu yenilenebilir enerji kaynaklarının kullanımı sayılabilir 
(Mutdoğan 2010, Keskin 2012, Fullagar,Wilson ve Markwell 2012).

Yavaş şehir yaklaşımının temelinde, şehirlerin daha yaşanılabilir yerler olması gelmektedir (Knox 2005, Uslu 2009). Bu tür şehirlerde, yaşam koşuşturma içinde geçmemekte, büyük alışveriş merkezleri yerine küçük dükkanlar ya da mini marketlerden alışveriş yapılmakta ve hatta semt pazarından doğal ürünler rahatlıkla satın alınarak restoran ya da evlerde tüketilebilmektedir. Gürültü kirliliği, trafikte beklerken kaybedilen zaman sonucunda ortaya çıan stres, şehir merkezinde ya da etrafında görselliği rahatsız eden bir yapılaşma gibi olumsuz örneklere rastlamak mümkün olmayabilir. İşte bütün bunlar, üretim yerine dünyanın kaynaklarını hızlı bir şekilde tüketime, koruma yerine kullanmayı teşvik eden metropol şehir mantığına alternatif olarak ortaya atılan "Yavaş Şehir" modelidir.

Metropol yaşamı ile yavaş şehir yaşamı arasındaki bu temel farklilik, sürdürülebilirlik anlamında doğrudan turizm sektörüne de hizmet vermektedir. Sahip olunan doğal, kültürel ve ekonomik kaynakların sadece günümüz insanları ya da turistinin temel ihtiyaçları için değil; aksine, ilerleyen yıllarda da benzer bir yaşama sahip olmayı hayal eden gelecek kuşakların ihtiyaçlarını da karşılayacak şekilde yaşam standartlarının koruma altına alınmasını hedefleyen bir anlayış biçimi olan sürdürülebilirlik, son yıllarda dünyanın birçok ülkesinde turizm sektörü açısından ayrıca ele alınmaya başlanmıştır. Çünkü turizm sektörünün doğrudan beslendiği doğal ve kültürel kaynaklar da kısıtlı düzeyde olup, sadece bugün için değil insanoğlu var olduğu sürece farklı zaman dilimlerinde turizm faaliyetlerine katılacak geleceğin turistleri için de temel bir gereklilik olacağ kuşkusuzdur.

Turizm sektöründe artan rekabet karşısında ülkeler, bir yandan bölgesel pazarları kontrol etmeye yönelik rekabet stratejileri uygulamaya çalışırken, diğer yandan da, diğer ülkeler ile belirli alanlarda işbirliğine dayalı stratejiler izlemektedirler. Ayrıca, sektörde turist davranışları ve beklentilerinin önemli ölçüde değiştiği görülmektedir. Şöyle ki, her ne kadar yavaş şehir kavramı, başlangıçta daha çok yerel halkın yaşam kalitesi için düşünülmüş olsa da, ilerleyen yıllarda turizm açısından bir çekicilik olarak tanıtılmaya başlanmıștır.
Geleceği tehlikeye atmadan, en iyi şekilde yararlanılması anlamında olan sürdürülebilirlik kavramı, destinasyonların sürdürülebilirliği açısından da önemlidir. Sürdürülebilirlik yalnızca doğal kaynaklar için değil aynı zamanda kültürel kaynaklar için de geçerli bir kavramdır. Turizmin etkilerinin yoğun olarak hissedildiği destinasyonlarda kültür ya da yaşam tarzında yozlaşmalar görülmekte ve tarihi mekanlar turist kalabalığından gördüğü fiziksel zarardan payını almaktadır. Turizmin geleceği açısından bu tür durumların önüne geçmek için gerekli tedbirlerin alınması ve politikaların belirlenmesi gerekmektedir.

Turizm ürünleri destinasyon kaynaklarına son derece bağlı olmakla birlikte bu kaynaklar turizm endüstrisinin kontrolünde değildir. Destinasyonlar turistler sayesinde popüler olmakta ancak aynı zamanda turizmin kendisi de destinasyonun çekiciliklerine zarar veren bir gelişim izleyebilmektedir. Dolayısıyla sürdürülebilir gelişim stratejileri, hem gelecek nesillerin ihtiyacını göz önünde tutarak geleceğe değer katmanın hem de kaynakları korumanın önemini vurgular. Sürdürülebilirlik turizm için önem taşımaktadır, çünkü turizm de bir bakıma madencilik gibi sınırlı kaynaklara sahip bir sektör olarak değerlendirilmektedir.

\section{Yavaș șehir - turizm paradoksu}

Dünyada sanayileşme sürecinin başlaması ile birlikte tarım toplumlarının kullandığı araç gereçler insan emeğinin yerini almaya başlamış ve kırsal alanlarda iş gücü fazlalığı ortaya çıkmıştır. Bu durum yoğun olarak tarımdan sanayiye ya da kırsaldan kente doğru bir göç hareketi oluşturmuştur (Cerrutti \& Bertoncello 2003, Zhang \& Song 2008). Dünyada olduğu gibi Türkiye'de bu süreçten etkilenmiş 1950'li yıllardan itibaren köyden kente göç hızlanmıştır (Güreşçi \& Yurttaş 2008).

Ülkemizde 1920'li yıllarda 10 kişiden 8'i kırsal yerleşim alanlarında yaşarken günümüzde 10 kişiden 8'i kentsel yerleşim alanlarında yaşamaktadır. Özellikle 1950'li yıllardan itibaren ekonomik faktörlerin etkisi ile kırsal yaşam alanlarından kentsel yaşam alanlarına yoğun bir göç yaşanmıştır (Anonim 2017). Kentleşmenin sonucu olarak hızlı yaşamın var olduğu, kültürel değerlerin unutulduğu, hızlı yemek, hızlı alış veriş, trafik, gürültü, hava kirliliği 
problemlerinin yaşandığı sağlıksız beslenen tüketim toplumları ortaya çıkmıştır. Toplumlar tüketim odaklı, hızlı yaşam biçiminin kendilerini mutsuz ettiğini fark edince yeni alternatif arayışlar içerisine girmeye başladılar. Tam da bu noktada yavaş şehir felsefesinin bir çıkış yolu olabileceği umudu oluştu.

Yavaş şehir kavramı, başlangıçta yerel halkın yaşam kalitesi için düşünülmüş olsa da, ilerleyen yıllarda turizm açısından da bir çekicilik olarak tanıtılmaya başlanmıştır. Sürdürülebilir turizm kapsamında da ele alınmaktadır. Bir yandan turizm alanında gelişmek isteyen destinasyonların yavaş şehir kavramı ile ön plana çıkması, bir yandan kentlerde modern ve hızlı yaşamın zorluklarından bunalmış insanların küçük kasabalara göç etmeye başlaması ile birlikte ülkemizde yavaş şehirlerde beklenenin aksine olumsuz gelişmeler yaşanmaya başlanmıştır.

Dünyadaki yavaş şehir uygulamalarını incelediğimizde ülkemizden farklı örneklerle karşılaşmaktayız. Mendrisio (İsviçre), kent yönetiminin enerji politikaları ile "enerji kenti" (Energiestadt) unvanını almıştır (Bott ve diğerleri, 2009, s.29). Überlingen (Almanya), 2004 y1lında çevresel yönetim sistemlerin arazi kullanımı planlamasını uyarlayan ilk Avrupa Birliği kenti olmuş ve sürdürülebilir arazi kullanımını ile ilgili planlar yapmaktadır (Knox ve Mayer, 2012, s. 62-63). Orvieto (İtalya), kent içi ulaşım sistemlerini yeniden yapılandırmış, karbon ayak izi bırakmayan teleferik hizmeti getirmiștir (Knox ve Mayer, 2012, s. 54). Levanto'da (İtalya) kent merkezi trafiğe kapatılmıştır. Levanto'da (İtalya), kamusal ve açık alanların yaşanabilirliğini arttırmak için kente özgü sokakları ve meydanlar iyileştirilmiş; tarihi meydanlar ve yapıların koruma ve restorasyon çalıșmaları yapılmış; diğer kentsel alanlar ise çağdaş bir yaklaşım ile yeniden tasarlanmıştır (Bott ve diğerleri, 2009, s.40).

Ludlow'da (İngiltere), geleneksel tekniklerin korunması için çıraklık sistemine dayanan bir eğitim programı başlatılmıștır (Pink, 2008, s.100). Ludlow'da (İngiltere), kent yönetimi kent planlaması konularında halkın da katılımı ile onaylanmıştır (Multinovic, 2010, s.7). Slow Food'un merkezi olan Bra'da (İtalya), okul kantinlerinde sağlıklı ve yerel öğünler sunulmaktadır (Bott ve diğerleri, 2009, s.35). Überlingen (Almanya), tarımda genetiği değiştirilmiş mikro organizma kullanmayı reddettiğini beyan etmiş ve gönüllü olarak 70'den fazla çiftçi toplam 200 hektarlık bir alanda bu doğrultuda tarım yapmayı onaylamıştır (Knox ve Mayer, 2012, s. 54).

Ülkemizdeki yavaş şehir uygulamalarının belediyelerin nezdinde olmas1 siyasi bir kurum olan belediyelerin yöneticilerinin değișmesi ile kriterlerin yerine getirilmesinde sorunlar yaşanma olasılığını da düşündürmektedir. Yasaların ülkeden ülkeye farklılık göstermesi yavaş şehirler ağ1 içinde bir bütünlük oluşturmanın önünde bir engel oluşturabilmektedir. Ülkemizde 2012 yılında büyük şehir yönetmeliğinde yapılan değişiklikle bazı iller büyük şehir statüsüne alınmış bu durum ilçelerin bazılarının mahalle olmasına bazılarının da sınırlarının ve nüfuslarının değişmesine neden olmuştur. Aydın, Ordu ve Muğla illeri 2012 yılında yapılan değişikliklerle büyük şehir oldukları için, bu bölgelerde bulunan ilçelerin bazıları mahalle olmuş, bazıları ise yeni mahallelerin eklenmesi ile birlikte nüfuslarında ciddi artışlar görülmektedir.

Akyaka (Muğla)2011 yılında yavaş şehir unvanını aldığında nüfusu 2.539 iken, Muğla ilinin 2012 yılında büyük şehir olması ile birlikte şu anda Ula ilçesinin bir mahallesi olmuştur. Ula (Muğla) ilçesinin 2017 yılındaki nüfusu24.419 dir. Bu nedenle Akyaka'nın yavaş şehir olup olmama durumu yeniden değerlendirilmeye alınmıştır. Ordu'nun Perşembe ilçesinde 4 yıl gibi kısa bir sürede ciddi bir nüfus artış1 görülmektedir. Perşembe (Ordu) yavaş şehir unvanını aldı ̆̆1 2012 yılında nüfusu 9.168 iken,2017 y1lında nüfusu 30.812 olmuştur. $\mathrm{Bu}$ artışın nedeni yavaş şehir unvanını almış olması ile bağlantılı olmadığı açıktır. Ülkemizin siyasi yapısına baktı̆̆ımız zaman yasa ve yönetmeliklerde yapılan değişiklikler yavaş şehirlerin nüfuslarını ve büyüklüklerini de etkilemektedir. Bu durumda siyasi yapımızla yavaş şehir uygulamalarının örtüşmeyen bir yanı olduğunu söyleyebiliriz.

Yavaş şehir üzerine yapılan çalışmaları incelediğimizde araştırmacıların olumlu ve olumsuz etkilerini değerlendirdiklerini görmekteyiz. Yapılan çalışmalarda ağırlıklı olarak olumlu yönlere değinilmiştir. Yavaş şehir unvanına sahip olmanın gerektirdiği kriterler şehirleri olumlu yönde geliştirmeyi, daha yaşanılır kentler yaratmayı, yerel halkın yaşam kalitesini yükseltmeyi hedeflemektedir. $\mathrm{Bu}$ kriterler doğrultusunda bu şehirlerde çevre düzenlemeleri, restorasyon çalışmaları, kültürel ve 
doğal varlıkların korunmasına yönelik çalışmalar yapılması gelmektedir.

Yavaş şehir kriterler içinde yerel üretimin desteklenmesi yer almaktadır. $\mathrm{Bu}$ amaçla küçük işletmelerin desteklenmesi, insan emeğinin değer bularak kadınların ve gençlerin üretime katılması için yeni istihdam alanlarının yaratılması ile sürdürülebilir yerel ekonomik bir kalkınma modeli hedeflenmektedir. Bu amaçla projeler geliştirilmekte, kooperatifler kurulmakta ve el sanatlarının korunması ve geliştirilmesine yönelik çalışmalar yapılmaktadır. $\mathrm{Bu}$ bölgelerin turizm çekiciliğinin artması ile birlikte ev pansiyonculuğunu geliştirmeye yönelik çalışmalar yapılmaktadır.

Tablo 1.Yavaş Şehir/Turizm konusunda daha önce yürütülen araştırmalarda ele alınan olumlu-olumsuz yönler

\begin{tabular}{|c|c|c|c|c|}
\hline No & Yazar/lar & $\begin{array}{c}\text { Çalışılan } \\
\text { Mekan/şehir }\end{array}$ & Olumlu yönler & Olumsuz yönler \\
\hline 1 & $\begin{array}{l}\text { Mutdoğan } \\
(2010)\end{array}$ & $\begin{array}{l}\text { Seferihisar, } \\
\text { İzmir }\end{array}$ & $\begin{array}{l}\text { Yaşam kalitesinin yükseltmesi, geçmiş } \\
\text { değerlere, kültüre, geleneklere ve } \\
\text { lezzetlere sahip çıkılması ve yaşatılması, } \\
\text { doğal çevrenin koruması. }\end{array}$ & \\
\hline 2 & $\begin{array}{l}\text { Şahinkaya } \\
\text { (2010) }\end{array}$ & Bra, İtalya & $\begin{array}{l}\text { Trafik sorunu ve gürültü olmaması, } \\
\text { bisiklet kullanımının yaygın olması, } \\
\text { reklam panoları ve çanak antenlerin } \\
\text { bulunmaması, binalar restore edilmiş, } \\
\text { yöresel yiyecekler üretimi, istihdam, gıda } \\
\text { festivali düzenlenmesi, geri dönüşüme } \\
\text { önem verilmesi, yerli ürünlerin üretim ve } \\
\text { satışı. }\end{array}$ & \\
\hline 3 & $\begin{array}{l}\text { Şahinkaya } \\
(2010)\end{array}$ & $\begin{array}{l}\text { Seferihisar, } \\
\text { İzmir }\end{array}$ & 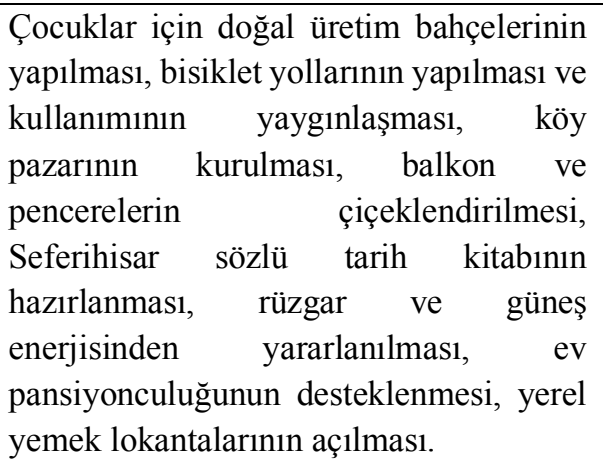 & \\
\hline 4 & $\begin{array}{c}\text { Yurtseven, } \\
\text { Kaya } \\
(2011)\end{array}$ & Seferihisar & $\begin{array}{l}\text { Yavaş şehir ve yavaş yemek hareketi } \\
\text { doğrudan turizm amaçlı değildir. } \\
\text { Destinasyon gelişimi ve kaliteli bir itibar } \\
\text { oluşturulabilir, Seferihisar'a gelen } \\
\text { turistleri adanmış, ilgili ve kazara turistler } \\
\text { olmak üzere üç gruba ayırmışlar. } \\
\text { Adanmış ve ilgilenen turistlerin yavaş } \\
\text { şehirlere olan ilgisi yüksek, bilinçli ve } \\
\text { çevreye duyarlı turistler. Yavaş turizm niş } \\
\text { turizm olarak algılanabilir. }\end{array}$ & $\begin{array}{l}\text { Kazara turistinin gelmesi, kitle } \\
\text { turizminin bir parçası olan turistler. }\end{array}$ \\
\hline
\end{tabular}

Yavaş şehir unvanını alan bölgelerde turizmin artması ile birlikte yeni istihdam alanları yaratılmış, araziler değer kazanmış ve halkın refah düzeyinde artış yaşanmıştır. Doğal ve kültürel mirasın öneminin anlaşılması ile doğal ve kültürel mirasın korunmasına yönelik uygulamalar başlatılmıştır. $\mathrm{Bu}$ uygulamalar arasında yenilenebilir enerji kaynaklarının kullanımı, geri dönüşüme önem verilmesi, çevreyi korumaya yönelik önlemler alınması, trafik sorununun çözümü, gürültü kirliliğinin önlenmesi ve çevre düzenlemeleri sayılabilir. Tüm bu çalışmalar o bölge hakkında olumlu imaj yaratılmasına katkı sağlamaktadır. 


\begin{tabular}{|c|c|c|c|c|}
\hline 5 & $\begin{array}{l}\text { Ergüven } \\
\text { (2011) }\end{array}$ & Vize & & $\begin{array}{l}\text { Cittaslowlaşmanın problemleri başlı̆̆ } 1 \\
\text { altında değinilmiştir. Yavaş şehirlerin } \\
\text { küreselleşmesi, aynı kriterler farklı } \\
\text { ölçüde uygulanması, elit olarak } \\
\text { algılanması. }\end{array}$ \\
\hline 6 & $\begin{array}{l}\text { Karabağ, } \\
\text { Yücel, } \\
\text { İnan } \\
(2012)\end{array}$ & Türkiye & $\begin{array}{l}\text { Özgünlük, kültürel çeşitlilik, marka } \\
\text { kimliği, destinasyonun tanıtımı, kültürel } \\
\text { mirasın korunması, kültür turizminin } \\
\text { gelişmesi, ekonomik büyüme, bölgeler } \\
\text { arasındaki gelir dağılımının eşitlenmesi, } \\
\text { halka ek gelir imkanları yaratması, } \\
\begin{array}{l}\text { sürdürülebilirlik } \\
\text { benimsenmesi, yerel hizmetlerin }\end{array} \\
\text { gelissmesi. }\end{array}$ & \\
\hline 7 & $\begin{array}{l}\text { Keskin } \\
(2012)\end{array}$ & Türkiye & $\begin{array}{l}\text { Yerel sürdürülebilir ekonomik kalkınma } \\
\text { modeli, yenilenebilir enerji kaynaklarının } \\
\text { kullanımı, yerel ürünlerin değer } \\
\text { kazanması, kentsel yaşam kalitesini } \\
\text { arttırmaya yönelik çalısmalar, doğal } \\
\text { kaynakların korunması, kültürel } \\
\text { zenginliklerin korunması ve dünyaya } \\
\text { tanıtılması. }\end{array}$ & \\
\hline 8 & $\begin{array}{l}\text { Sirrım } \\
(2012)\end{array}$ & Türkiye & $\begin{array}{l}\text { Yerel ekonomide canlanma, istihdam ve } \\
\text { refah artışı, farklı ve özgün tarzlarıyla } \\
\text { yavaş şehirler turistik cazibe haline } \\
\text { gelmekte, ana girdisinin turizm } \\
\text { gelirlerinden oluştuğu yerel ekonomik } \\
\text { kalkınma modeli oluşmakta. }\end{array}$ & $\begin{array}{l}\text { Avustralya'nın bir zamanlar gelişen } \\
\text { bir nehir limanı şehri Goolwa'nın, } \\
\text { Sakin Şehir olduktan sonra turist } \\
\text { akınına uğradığını, tarihi binalardaki } \\
\text { sanat galerilerinin, kafelerin ve küçük } \\
\text { pansiyonların ziyaretçilerin hizmetine } \\
\text { sunulduğunu görüyoruz (Serin, 2009). }\end{array}$ \\
\hline 9 & $\begin{array}{l}\text { Sungur } \\
(2013)\end{array}$ & $\begin{array}{l}\text { Mevcut Yavaş } \\
\text { Şehirler }\end{array}$ & $\begin{array}{l}\text { Ev pansiyonculuğu, halıcılık, deri ve } \\
\text { keçeden el sanatları, geleneksel } \\
\text { lezzetlerin üretilmesi, hayvancılık ve } \\
\text { organik tarımın gelişmesi, kooperatiflerin } \\
\text { kurulması. }\end{array}$ & \\
\hline 10 & $\begin{array}{l}\text { Coşar } \\
(2013)\end{array}$ & $\begin{array}{l}\text { Seferihisar, } \\
\text { İzmir }\end{array}$ & $\begin{array}{l}\text { Ek gelir yaratılması, organik tarımın } \\
\text { teşvik edilmesi, kadınların üretime } \\
\text { katılması, yeni istihdam alanlarının } \\
\text { yaratılması, arazinin değer kazanması. }\end{array}$ & $\begin{array}{l}\text { Trafik ve gürülttünün artması, } \\
\text { yapıllaşmanın artması, fiyat artışı, } \\
\text { nüfus artışı, hızlı yapılaşma, rant artışı } \\
\text { ile birlikte sit alanlarının yapılaşması, } \\
\text { büyük otellerin kurulması, otopark } \\
\text { sorunu, göç, kültürel yozlaşmaya, } \\
\text { dokusunun bozulması, halkın bilinçsiz } \\
\text { ve kısa vadeli çıkarlarını düşünmesi, } \\
\text { çok fazla bilinirliğinin artması ile } \\
\text { birlikte büyük şehre yakın olduğu için } \\
\text { korunması zor bir bölge, } \\
\text { yatırımcıların ilgisini çekmesi. }\end{array}$ \\
\hline 11 & $\begin{array}{l}\text { Çakıcı, } \\
\text { Yenipınar } \\
\text { ve Benli } \\
(2014)\end{array}$ & $\begin{array}{l}\text { Seferihisar, } \\
\text { İzmir }\end{array}$ & $\begin{array}{lcr}\text { İstihdam } & \text { artışı, kamu } & \text { hizmetlerinin } \\
\text { gelişmesi, } & \text { yaşam } & \text { standartlarının } \\
\text { yükselmesi, } & \text { yerel } & \text { ekonominin } \\
\text { canlanması, yatırımların } & \text { artması, yeşil } \\
\text { alanların ve doğal kaynakların korunması. }\end{array}$ & \\
\hline
\end{tabular}




\begin{tabular}{|c|c|c|c|c|}
\hline 12 & $\begin{array}{l}\text { Şahin, } \\
\text { Kutlu } \\
\text { (2014) }\end{array}$ & Türkiye & $\begin{array}{llrr}\text { Yavaş şehir ve sürdürülebilir } & \text { kalkınma } \\
\text { anlayışı birbirini } & \text { teorik } & \text { olarak } \\
\text { desteklemektedir. } & \text { Alışıldık } & \text { turizm } \\
\text { anlayışının yavaş } & \text { şehirle } & \text { birlikte } \\
\text { değiş̧eceği, geri } & \text { dönüşüume } & \text { önem } \\
\text { verilmesi. } & & & \end{array}$ & $\begin{array}{l}\text { Büyük kentler açısından Cittaslow'un } \\
\text { uygulanabilirliğinin nüfus kıstas } \\
\text { nedeniyle olmaması, } \\
\text { Siyasal bir kurum olan belediyeler } \\
\text { nezdinde üye olunması devamll bir } \\
\text { bağlılık, açısından risk oluşturabilir. } \\
\text { Yasaları ülkeden ülkeye farklı } \\
\text { oluşu çevre, ekonomi ve yaşam } \\
\text { parametreleri alanında da bir } \\
\text { çeşitliliğe neden olmaktadır. Bu } \\
\text { durum birlik içinde yekpare bir } \\
\text { yapının oluşması önünde bir engel } \\
\text { teşkil etmektedir. }\end{array}$ \\
\hline 13 & $\begin{array}{l}\text { Karadeniz } \\
\text { (2014) }\end{array}$ & $\begin{array}{l}\text { Perşembe, } \\
\text { Ordu }\end{array}$ & $\begin{array}{l}\text { Doğal ve kültürel kaynakların korunması, } \\
\text { bozulmamış doğa ve kültürün } \\
\text { değerlendirilmesi, yerel üretimin ve } \\
\text { küçük işletmelerin desteklenmesi, yavaş } \\
\text { şehir unvanını alarak imaj oluşturmak, } \\
\text { organik tarımın yaygınlaşması, insan } \\
\text { emeğinin değer bulması, görüntü } \\
\text { kirliliğinin en aza indirgenmesi, yerel } \\
\text { halkın yaşam kalitesinin artmasını } \\
\text { desteklemesi. }\end{array}$ & $\begin{array}{l}\text { Halkın bilinçli olmaması, yavaş olarak } \\
\text { algılanmak, lüks tüketim olarak } \\
\text { algılanması, ilerleyen zamanda talebin } \\
\text { karşılanamaması, } \\
\text { edilememesi ve yönlendirilememesi, } \\
\text { sürdürülebilirliğin üç boyutu arasında } \\
\text { çatışma yaşanması, halkın tepkisi, } \\
\text { yavaş seyahat eden turistlerin } \\
\text { beklentilerini karşılayamamak. }\end{array}$ \\
\hline 14 & $\begin{array}{l}\text { Tunçer ve } \\
\text { Olgun } \\
(2017) \\
\end{array}$ & Seferihisar & $\begin{array}{l}\text { Ekonomik mali yapı, kadın istihdamı ve } \\
\text { yenilenebilir enerji üzerine etkilere } \\
\text { değinilmiş. }\end{array}$ & $\begin{array}{l}\text { Şehirlerin tanııırlı̆ı arttıkça nasıl bir } \\
\text { sonuç doğacağı tahmin edilememesi } \\
\text { ve nüfus artış1. }\end{array}$ \\
\hline 15 & $\begin{array}{l}\text { Özmen ve } \\
\text { Can (2018) }\end{array}$ & $\begin{array}{l}\text { Mevcut Yavaş } \\
\text { Şehirler }\end{array}$ & Cittaslow Hareketi’ne Eleştirel Bir Bakış & $\begin{array}{l}\text { Seferihisar'da emlak piyasasının } \\
\text { hareketlenmesi, göç alması, } \\
\text { soylulaşma riski, yöre halkının fazla } \\
\text { katılım göstermemesi, yerel } \\
\text { yönetimlere ve siyasete bağıml } \\
\text { olması, yavaş şehirlerin ekonomik } \\
\text { odaklı görülmesi sonucu plansız ve } \\
\text { kontrolsüz turizm gelişimi. }\end{array}$ \\
\hline
\end{tabular}

Araştırmalar yavaş şehir unvanına sahip olan bölgelerde turizmin ve arazi değerlerinin artmasının ilk yıllarda olumlu algılandığını zamanla bu durumun olumsuz yönlerinin ortaya çıktığını göstermektedir. Özellikle bu bölgelerde göç ile birlikte nüfus artış1 görülmekte bu durum trafik ve gürültü kirliliğine yol açmakta, arazinin değer kazanması ile rant oluşmakta ve fazla yapılaşma görülmektedir. Bunun sonucu olarak bu şehirlerde de büyük şehirlerde yaşanan karmaşa yaşanmaya başlamaktadır.

Araştırmaların sonuçlarını değerlendirdiğimizde yavaş şehirlerin varoluş amacı ile ülkemizdeki algılanış1 ve uygulama biçiminden kaynaklanan farklılıklar dikkati çekmektedir. İlk yıllarda yavaş şehirlerin görmüş olduğu ilgi olumlu algılanırken ilerleyen yıllarda artan talebin karşılanamaması olumsuz sonuçlar doğurabilir. Turizmin plansız gelişiminin sonuçlarında biri olan kapasite aşımı yavaş şehirler için gelecekte olası sorunlar arasında yer alabilir. Yavaş şehir anlayışının sadece ekonomik gelişme olarak görülmesi de gelecekte bu şehirlerin dokusunun bozulmasına ve yerel halkın yaşam kalitesinin düşmesine yol açabilir.

\section{Sonuç}

Yavaş şehir üyelik sürecinde yapılan çalışmalar sürdürülebilirlik ilkesi ile örtüşmekte ve destinasyonlara kentsel tasarım, yerel üretim, kentsel yaşam kalitesi ve yenilenebilir enerji, kullanımı için farklı bakış açıları ve fırsatlar sunmaktadır. Sosyal ve kültürel yönde olumlu değişimler ile yaşam kalitesinin arttırması hedeflemektedir. Uluslararası bir birlik olması örgüt içerisinde işbirliği ve güç ile başarıyı 
arttırmaktadır. Yavaş şehir anlayışının benimsenmesinde yerel yönetimlerin, halkın ve karar vericilerin işbirliği büyük önem arz etmektedir. Olumlu bir bakış açısıyla kurulmuş uluslararası bir birlik olmasına karşın bazı yavaş şehirlerde olumsuz durumlarla da karşı1laş1labilmektedir. Yerel bir hareket olarak, yerel değerlerin korunması ilkesi benimsenmiş olsa da küreselleşme yönünde gelişmeler görülmektedir.

Yavaş şehir yerel kalkınma modelini benimseyen, sürdürülebilirlik ilkesi ile hareket eden bir anlayışla kurulmasına karşıllk yerel halk tarafindan bir rant kapısı olarak görülebilmektedir. Yerel halkın böyle bir yaklaşım içinde olmaması için öncelikle yavaş şehir anlayışını benimsemesi gerekmektedir. Yerel halk ne kadar katılım gösterirse yavaş şehir farkındalığı ve başarısı o derece artacaktır. Yavaş şehirde yaşamanın ayrıcalık olarak görülmesi bu şehirlere olan talebi artırmaktadır. Bu durum yavaş şehirlerin göç almasına ve bunun sonucunda nüfus artışı, trafik ve gürültü sorunlarına, konut ve arsa fiyatlarında artışa neden olmaktadır. Yavaş şehir sayılarında görülen artış farklı ve özel olma algısını zamanla ortadan kaldırabilir ve şehirlere olan ilgiyi azaltabilir (Knox, 2005).

Özgün ve yerel değerlerin ekonomik kalkınma odaklı ele alınması bölgeye yeni yatırımları çekmekte ve turizmin hızla gelişimini desteklemektedir. Kontrolsüz ve plansız turizm gelişimi bölgede kitle turizminin gelişimine neden olabilir. Oysa yavaş şehir anlayışı kitle turizmine karşı duran bir anlayıştır. Ancak yerel halkın beklentisi bu unvana sahip olmakla birlikte ekonomide ve turizmde beklenen hizlı gelişmeler olduğu görülmektedir.Yavaş şehir ve turizm konulu çalışmaların çoğunda ekonomik gelişim potansiyeli üzerine vurgu yapıldığ görülmektedir.

Yavaş şehirlerin pazarlanması ve tanıtımı için fazla reklam yapılması bu bölgelere olan ilgiyi arttırmaktadır. Bunun sonucunda bazı yavaş şehirlerde aşrı talep artış1 görülmektedir. Zaman içerisinde oluşan talebin karşılanmasında, yönlendirilmesinde ve kontrol edilmesinde sorunlar yaşanabilir. Bu bakımdan yavaş şehirler sadece turizm gelişimine odaklanmamalı ve bu şekilde pazarlanmasının doğuracağı olumsuzluklar göz önünde bulundurulmalıdir.

Kısa vadeli çıkarların düşünülmesi kültürel yozlaşmaya, şehrin dokusunun bozulmasına ve yerel özelliklerin kaybolmasına neden olmaktadır. $\mathrm{Bu}$ şehirlere olan talebin artması zamanla talebin karşılanamaması ve kontrol edilememesi riskini oluşturmaktadır. Turizmde daha çok niş pazara hitap etmesi gereken yavaş şehirler kitle turizminin bir parçası olan destinasyonlara dönüşerek özelliğini kaybetme riski ile karşı karşıya kalacaktır. Şehirlerin dokusuna uymayan büyük otel ve tatil köylerinin bulunduğu destinasyonlar haline gelme riski taşımaktadırlar.

Ülkemizde yerel seçimler 5 yılda bir yapılmakta ve bu süre sonunda yerel yöneticiler değișebilmektedir. $\mathrm{Bu}$ durum yerel yöneticinin değişimi ile birlikte yavaş şehir anlayışının sürdürülebilirliğini de etkilemektedir. Bunun sonucunda aynı kriterler farklı şehirlerde farklı biçimlerde uygulanabilmektedir. Yavaş şehir unvanına sahip kentlerin siyasetten bağımsız, yerel yönetimler üstü bir kuruluş tarafindan yönetilmesi sürekliliğin sağlanması açısından önem arz etmektedir.

\section{Kaynakça}

Anonim, (2017). http://www.hips.hacettepe.edu.tr/ TurkiyeninDemografikDonusumu_220410.pdf.(Erişim Tarihi: 01.02.2017).

Bott, H., Sgobba, A. \&Busch S. (2009). Slow City Concepts. Stuttgart:Universität Stuttgart Städtebau-Institut.

Cerrutti, M. \& Bertoncello R. (2003). Urbanization and Internal Migration Patterns in Latin America.Conferance on African Migration in Comparative Perspective, Johannesburg, Africa, June 4-7.

Coşar, Y. (2013) Yavaş șehir (cittaslow) olgusunun turist davranışları ve yerel halkın kentsel yaşam kalitesi algısına etkileri. Dokuz Eylül Üniversitesi, Sosyal Bilimler Enstitüsü, Doktora Tezi.

Çakıcı, A. C., Yenipınar, U. \& Benli, S. (2014). Yavaş şehir hareketi: Seferihisar halkının tutum ve algıları ile yaşam doyumları. Seyahat ve Otel İsletmeciliği Dergisi, 11 (3): 26-41.

Ergüven, M. H. (2011). Cittaslow - yaşamaya değer şehirlerin uluslararası birliği: Vize örneği.Organizasyon ve Yönetim Bilimleri Dergisi, 3(2): 1309 -8039 (Online).

Fullagar, S., Wilson, E. \& Markwell, K. (2012). StartingcSlow: Thinking Through Slow Mobilities and Experiences, İçinde Slow Tourism: Experiences and Mobilities, S. Fullagar, E. Wilson ve K. Markwell (Editörler). Bristol: Channel View Publications.

Güreşçi, E. \& Yurttaş Z. (2008). "Kırsal Göçün Nedenleri ve Tarıma Etkileri Üzerine Bir Araştırma: Erzurum İli İspir İlçesi Kırık Bucağı Örneği”.Tarım Ekonomisi Dergisi, 14(2), 47-54. 
http://cittaslowturkiye.org/\#cittaslow (Erişim Tarihi: 01.02.2017).

http://www.bagimsizsosyalbilimciler.org/.Yazilar_Uye/Sah inTem10.pdf(Erişim Tarihi: 10.11.2017).

Karabağ, O., Yücel, F. \& İnal, M. E. (2012).Cittaslow movement: an opportunity for branding small towns and economic development in Turkey. International Journal of Economic-Research, 3c(3): 64-75.

Karadeniz, C.,B. (2014) Sürdürülebilir turizm bağlamında sakin şehir Perşembe. Uluslararası Sosyal Araştırmalar Dergisi. $\quad$ Cilt: $\quad 7, \quad$ Say1: 29: 13079581.http://www.sosyalarastirmalar.com/cilt7/sayi29pd f/bahtiyar_cemile.pdf.(Erişim Tarihi: 05.04.2017)

Keskin, E. B. (2012). Sürdürülebilir kent kavramına farklı bir bakış: yavaş şehirler (Cittaslow). ParadoksEkonomi, Sosyoloji ve Politika Dergisi, Cilt:8, Sayı:1, s. 81.

Knox, P.L. (2005). Creating ordinary places: Slow cities in a fast world.Journal of Urban Design, 10 (1):1-11.

Knox, P.L. \& Mayer, H. (2012). Small Town Sustainability: Economic, Social and Environmental Innovation.Basel:Birkhäuser.

Mayer, H. \& Knox, P.L. (2006). Slow cities: Sustainable places in a fast world.Journal of Urban Affairs, 28 (4): 321-334.

Milutinovic, S. (2010). Cittaslow Movement Ludlow UK. Urban SustainableDevelopment: A European Perspective, 1-10.

Mutdoğan, S. (2010). Seferihisar örneğinde sakin şehir hareketi / understanding the cittaslow movement through a seferihisar - case study. Gren Age Symposium, ss. 1 10. Mimar Sinan Fine Arts University, Faculty of Architecture 6-8 December 2010, İstanbul.

Özmen, A.,\& Can, M. C. (2018). Cittaslow hareketi'ne eleştirel bir bakış. Planlama,28(2):91-101. | Doi: 10.14744/planlama.2018.95967.

Pink, S. (2008). Re-thinking contemporary activism: From community to emplaced sociality. Ethnos, 73(2), 163188.

Sırım, V. (2012). Çevreyle bütünleşmiş bir yerel yönetim örneği olarak "sakin şehir" hareketi ve Türkiye'nin potansiyeli. Tarih Kültür ve Sanat Araştırmalart Dergisi,Say1:1, No.4, 2012, s.119-131.

Sungur, Z. (2013), Women Entrepreneurship in Slow Cities of Turkey from a Sociological. International Conference on Eurasian Economies, St. Petersburg, http://www.eecon.info/?p=13paperdetail\&id=786. (Erişim Tarihi: 19.01.2017).

Şahin, İ. \& Kutlu, S., Z. (2014). Cittaslow: Sürdürülebilir kalkınma ekseninde bir değerlendirme. Journal of Tourism and Gastronomy Studies, 2/1 (2014) 55-63.

Şahinkaya, S., (2010). Bir yerel kalkınma modeli: Cittaslow Seferhisar üzerine değerlendirmeler.
Tunçer, M. \& Olgun, A. (2017). Seferihisar'ın Ekonomik ve Mali Yapısı Üzerinden Sakin Şehir Uygulamalarına İlişkin Bir İnceleme, International Journal of Economics and Innovation 3(1):47-47. DOI:10.20979/ueyd.297748

Uslu, A., (2009). Sürdürülebilir Yeşil Kent Fikirleri, Örnekleri ve Türkiye İçin Dersler.21. Uluslararası Yapı ve Yaşam Kongresi Bildiriler Kitabı, Bursa: TMMOB Mimarlar Odası Yayını.

Yurtseven, H. R. \& Kaya, O. (2011). Slow tourists: A comparative research based on cittaslow principles.American International Journal of Contemporary Research, 1 (2): 91-98.

Zhang, K. H. \& Song S. (2008). Rural -urban Migration and Urbanization in China Evidence From Time- Series and Cross- Section Anayses.China Economic Rewiew, (14), 386-400. 


\section{Extended abstract in English}

When the world tourism sector faced serious problems before entering the new millennium, the question of "what could be done?" started to be asked more intensely in order to make us think. What were these problems? Firstly, it was marketing of certain types of products. The other problem was that tourism activities were similar in countries or regions. Therefore, different regions or countries had to meet the tourism market by introducing alternative products.

While focusing on individual tourism, mass tourism has emerged such as emergence of luxury tourism, coastal tourism, social and culture/city tourism. Similarly, as in hotels, all-inclusive concept has emerged as an alternative product to bed \& breakfast or half-board. Perhaps in the future, nothing inclusive could be an alternative product to all inclusive. Suddenly slow-food appeared as an alternative to fastfood. With the success of the slow food movement, the concept of slow-city came out. This study focuses on the concepts of slow city and slow tourism which are alternative to mass tourism made with package tours, and the study will analyse how these two terms conflict with each other in tourism context.

The concept of slow city and sustainable development supports each other. The purpose of concept of slow cities is to increase public investment and living standards in cities, to revive the local economy, to protect and maintain cultural and natural resources. However, in recent years, especially when the slow cities examined in our country, some developments that go against the spirit slow city has emerged. This study aims to form a critical view by slow city practice in our country and the aim of slow cities.

The research on the slow city accession process align with the principle of sustainability and offer different perspectives and opportunities for urban design, local production, urban quality of life and renewable energy use. The positive changes in social and cultural aspects of the city improves the quality of life. The cooperation of local governments, the public and decision-makers is of great importance in the formation of the slow city concept. Slow city is an international union and this increases the success and cooperation within the organization. Despite this, there may be some problems in slow cities. As a local movement, the principle of the protection of local values has been adopted but globalisation also plays a role in this process.

Local people may regard slow city as a source of commerce to make profit although it was established to support local development and adopted principle of sustainability. In order to avoid such a profit-based approach, the local people should first adopt a slow city approach. The more the local people participate, the more slow city awareness will increase. Living in a slow city is also considered as a privilege, which increases the demand for these cities. This causes slow cities to receive migration and they face population growth, traffic and noise problems, and increase in housing and land prices. The increase in the number of slow cities can disrupt the perception of being different and special and decrease the interest in cities (Knox, 2005).

The focus on the development of original and local values and economic development attracts new investments in the region and supports the rapid development of tourism. Uncontrolled and unplanned tourism development may lead to mass tourism in the region whereas slow city is based on an understanding against mass tourism. However, there are rapid developments in economy and tourism and in most of the slow city and tourism studies, there is an emphasis on potential economic development.

Increasing advertisement, marketing and promotion of slow cities increases interest in these regions. As a result, there is an increasing demand in some slow cities, which may create problems in meeting and controlling this demand. In this respect, slow cities should not only focus on tourism development, but also the possible disadvantages the marketing may bring.

The consideration of short-term interests causes cultural degeneration, deterioration of the city's structure and loss of local characteristics. Although the demand for these cities increases, there is always a risk of not being able to meet and control this demand. The slow cities need to address the niche market in tourism but they face the risk of losing their fame by turning into destinations that are part of mass tourism. They may also become a destination with large hotels and holiday villages that do not fit the spirit of the cities. 
In Turkey, local elections are held every 5 years and at the end of this period, local administration can change. This situation affects the sustainability of the slow urban understanding with the change of the local administration. As a result, the same criteria can be applied in different ways in different cities. It is important that the cities with slow city title are managed by an independent local administration units which do not have any political influence on them. 